\title{
PROSTAGLANDIN LEVELS IN GINGIVAL CREVICULAR FLUID IN PERIODONTITIS PATIENT WITH HYPERTENSION
}

\author{
RADITYA PRIHARNANTO ${ }^{1}$, ROBERT LESSANG ${ }^{2}$, SRI LELYATI C MASULILI ${ }^{2 *}$, FATIMAH MARIA TADJOEDIN ${ }^{2}$, \\ HERLIS RAHDEWATI ${ }^{2}$, PITU WULANDARI ${ }^{3}$, ELZA IBRAHIM AUERKARI ${ }^{4}$
}

${ }^{1}$ Periodontology Residency Program, Faculty of Dentistry, Universitas Indonesia, Jakarta, Indonesia. ${ }^{2}$ Department of Periodontology, Faculty of Dentistry, Universitas Indonesia, Jakarta, Indonesia. ${ }^{3}$ Department of Periodontology, Faculty of Dentistry, Universitas Sumatera Utara, Medan, Indonesia, Indonesia. ${ }^{4}$ Department of Oral Biology, Faculty of Dentistry, Universitas Indonesia, Jakarta, Indonesia.

Email: srilelyati@yahoo.com

Received: 31 July 2019, Revised and Accepted: 01 June 2020

ABSTRACT

Objective: Periodontitis is an infection that involved tooth-supporting tissues by dental plaque biofilm on the tooth surface and host immune response as causal to as inflammation resolution. Prostaglandin $\mathrm{E}_{2}$ (PGE2) as an inflammatory mediator has been implicated in the pathogenesis of various chronic inflammatory diseases, including periodontitis, and as a regulator of blood pressure. This study aims to compare the levels of prostaglandin in the gingival crevicular fluid (GCF) of periodontitis patients with hypertension and non-hypertension.

Methods: A total sample of 62 patients was examined and consists of 44 patients (aged 50-90 years) who were hypertension group and 18 patients (aged 30-49 years) who were non-hypertension groups as a control. Hypertension state was measured by blood pressure based on anamnesis and using sphygmomanometer mercury. The clinical sample was collected from 62 gingival crevicular fluids [GCF] of periodontal disease subject. Measurement of the clinical parameter of probing pocket depth [PD], and bleeding on probing [BOP $\geq 1]$ was included as a diagnostic requisition. The PD and clinical attachment loss [CAL] was defined as present if the PD was $\geq 5 \mathrm{~mm}$ and CAL was $\geq 1 \mathrm{~mm}$. Prostaglandin E2 level was estimated in gingival crevicular fluid samples by using the enzyme-linked immunosorbent assay.

Results: The level of PGE2 was statistically significant difference in hypertension patient compare with non-hypertension $(\mathrm{p}<0.05)$. There was a significant difference in PD, recession, and CAL $(\mathrm{p}<0.05)$.

Conclusion: Higher blood pressure might be related to the potential risk of inflammation and progression periodontal disease.

Keywords: Prostaglandin $\mathrm{E}_{2}$, Periodontitis, Hypertension, Inflammation.

(c) 2020 The Authors. Published by Innovare Academic Sciences Pvt Ltd. This is an open access article under the CC BY license (http://creativecommons. org/licenses/by/4. 0/) DOI: http://dx.doi.org/10.22159/ijap.2020.v12s2.0P-58

\section{INTRODUCTION}

Life expectation was increased in a person who is seen in older adult populations in developing countries. Among the potential targets for improving the health of older adults, hypertension represents one of the most prevalent and potentially modifiable conditions. Hypertension remains a major worldwide problem and is a condition that is often diagnosed in primary health care. In 2008 , approximately $40 \%$ of adults aged $\geq 25$ years were diagnosed with hypertension worldwide [1]. This number has increased in recent years from 600 million people in 1980 to a billion people in 2008 [1]. The highest prevalence of hypertension was found in the African region, which was estimated at $46 \%$ in adults aged $\geq 25$ years, whereas the lowest prevalence was found in the United States of America at 35\% [2]. A study mentioned that cases of hypertension that have been diagnosed by health personnel or people taking anti-hypertension drugs remain low in Indonesia at $24.2 \%$, suggesting that $75.8 \%$ of hypertension cases in the community have not been identified by the health service [3]. Ideally, the normal blood pressures are $120 / 80 \mathrm{mmHg}$. Hypertension is defined if individuals have blood pressures $\geq 140 / 90 \mathrm{mmHg}$ [3].

Periodontal disease is a chronic inflammatory disease resulted in progressive destruction in the supporting structures of teeth which are the gingiva, periodontal ligament, cementum, and alveolar bone, and is caused by interactions between bacteria and host immune system [4]. Lipopolysaccharides produced by bacteria trigger the production of tumor necrosis factor-alpha, interleukin-1ß, and prostaglandin $E_{2}$ (PGE2) from macrophages, fibroblasts, and inflammatory cells in periodontal tissues [4]. The activity of inflammatory responses and the associated molecules can cause damage to the tissue and alveolar bone. The development of the advanced periodontal disease can result in clinically periodontal pocket formation, changes in height and density of subjacent alveolar bone, and recession of the marginal gingiva also present [4]. Continued bleeding with probing during sequential visits has proved to be a reliable indicator of the presence of inflammation and increased risk for progression of attachment loss at the bleeding site $[4,5]$.

Periodontal disease has a potential relationship with cardiovascular disease because there was a possible association in chronic inflammatory conditions with systemic markers of inflammation and endothelial dysfunction. There were several research studies suggested a possible relationship between chronic inflammation and hypertension. Holmlund et al. reported a relation between periodontal disease severity and hypertension [6]. Contradictory, the study analysis of the Health Professionals Follow-Up Study did not show any significant associations between periodontal disease and hypertension diagnosis over 20 years of follow-up [7]. The Third National Health and Nutrition Examination Survey data result did not show any association between the severity of periodontal disease and blood pressure measurement [8].

PGE2 is the dominant prostanoid of arachidonic acid (AA) and involved in various biological systems such as the cardiovascular, endocrine, gastrointestinal, neural, and reproductive systems; it is also involved in the regulation of blood pressure through vasodepressor and/or vasopressors. PGE2 has subtype receptors known as E-prostanoid (EP) 
receptor and divided into four receptors (EP1, EP2, EP3, and EP4) that are mediated by G-coupled proteins which encoded by different genes and expressed differently in each tissue [9]. The previous studies have determined that the EPs expressed differently while particularly the EP1 and EP3 receptors mediated the pressor response and the EP2 and EP4 receptors mediate the depressor response [9].

PGE2 also plays a role in the pathogenesis of chronic inflammatory diseases, including periodontitis. It is a key regulator in the expression of the receptor activator of nuclear factor- $\mathrm{KB}$ ligand along with IL-6 [10]. Several studies stated that PGE2 and IL-6 were increased in patients with periodontitis [11]. It participates in the inflammatory response. Pro-inflammatory effects of PGE2 are increasing vasodilatation, enhancing responsiveness of receptors to painful stimuli, releasing of collagenase by inflammatory cells and activation of osteoclast, thereby causing bone resorption [12]. PGE2 also plays an important role in blood pressure regulation as a vasodepressor or vasopressor in blood vessels. This study aims to compare the levels of prostaglandin in the gingival crevicular fluid (GCF) of periodontitis patients with hypertension and non-hypertension.

\section{METHODS}

This study was approved by the Ethics Committee of the Faculty of Dentistry of Universitas Indonesia (no. 98/Ethical Approval/ FKGUI/V/2019). Clinical samples were collected from RSKGM Universitas Indonesia patients. The laboratory work was conducted at the Integrated Laboratory, Faculty of Medicine, Universitas Indonesia.

This work followed an observational study design, in which 62 GCF samples from individuals aged between 30 and 90 years $(23$ men and 39 women) were collected between February and June 2019. All the patients provided written informed consent to participate in this study. Complete anamnesis was performed by asking participants about their chief complaints, medical history, information about any allergies, systemic condition, use of medication, smoking habits, tooth brushing habits, etc. Detailed information included extraoral and intraoral checks, measuring participant's oral hygiene index, pocket depth (PD), recession, clinical attachment loss (CAL), and bleeding on probing (BOP).

The inclusion criteria were patients with periodontitis Stage II and III according to the criteria of the World Workshop on the Classification of Periodontal and Peri-Implant Diseases and Conditions 2017 [13]. The clinical parameters that comprise these criteria are PD $\geq 4 \mathrm{~mm}$, BOP score $\geq 1$, and CAL $\geq 1 \mathrm{~mm}$. The exclusion criteria were patients with a history of bruxism or smoking, intake of drugs during the past 6 months, pregnancy or breastfeeding, scaling $\leq 6$ months, or consumption of antibiotics $\leq 3$ months. Patients who were not taking medication or treatment for hypertension were included in the control group.

Blood pressure was measured using a mercury sphygmomanometer more than once when individuals were in a calm state [14]. The blood pressure of the patients was measured when they were seated, with their elbow bent on the table, palm facing up, and their arm placed higher than their heart [15].

Periodontal clinical examinations for BOP and PD were recorded using a Periodontal Probe UNC 15 (Osung Mnd, Korea). BOP was recorded as local bleeding present $30 \mathrm{~s}$ after probing using a scale from 0 to 4 (from no bleeding to widespread bleeding). Following this examination, GCF samples were as collected from each individual after removal of the supragingival plaque. GCF was obtained in the study group patients with $\mathrm{PD} \geq 4 \mathrm{~mm}$ and also from the control group patients.

The tooth surfaces were dried and isolated using cotton rolls. Three paper points (no. 25) was inserted into the periodontal pockets and held them in place for between 20 and $30 \mathrm{~s}$. The paper points were then placed into sterile Eppendorf tubes comprising $200 \mu \mathrm{l}$ of phosphatebuffered saline, refrigerated, and immediately transferred to the oral biology laboratory for analysis. The Eppendorf tubes comprising the samples were stored at $-70^{\circ} \mathrm{C}$.

The sample was tested by a competitive ELISA principle. The microELISA plate provided with the kit had been pre-coated with PGE2. During the reaction, PGE2 in the sample or the standard competes with a fixed amount of PGE2 on the solid phase supporter for sites on the biotinylated detection ab $50 \mu \mathrm{L}$ specific to PGE2 then incubated for $45 \mathrm{~min}$ at $37^{\circ} \mathrm{C}$. Excess conjugate and unbound sample or standard were washed from the plate, avidin conjugated with horseradish peroxidase was added to each microplate well in the amount of $100 \mu \mathrm{L}$, and the microplates were incubated for $30 \mathrm{~min}$ at $37^{\circ} \mathrm{C}$. Next, $3,3^{\prime}, 5,5^{\prime}$-tetramethylbenzidine substrate solution was added to each well. The enzyme-substrate reaction was terminated by the addition of a stop solution and the color change was measured spectrophotometrically at $450 \pm 2 \mathrm{~nm}$. The concentration of PGE2 in the samples was determined by comparing the optical density of the samples using the standard curve.

\section{Statistical analysis}

All statistical data analyses were performed using the SPSS software program (SPSS, Chicago, USA) with a significance level of 5\%. Age, plaque index, calculus index, debris index, oral hygiene index, PD, recession, CAL, and BOP were expressed by means and standard deviation. The data normality was using Kolmogorov-Smirnov stated that a total sample was 62 subjects. Data distribution resulted that the total sample in the inclusion group used a non-parametric test ( $p>0.05)$. A Mann-Whitney test was used to compare the level of PGE2 in subjects with hypertension and non-hypertension.

\section{RESULTS AND DISCUSSION}

A total of 62 participants agreed to retrieve their blood pressure status and a single site of the gingival crevicular area inspection. The participant's hypertension state was established with measured systolic and diastolic $>140 / 90 \mathrm{mmHg}$.

Table 1 shows the data distribution on the periodontal parameter of the two groups based on blood pressure status (hypertension and nonhypertension). Plaque index, calculus index, debris index, recession, and BOP data were not normally distributed with $p>0.05$. The mean PD was $5.47 \pm 1.13 \mathrm{~mm}$ (hypertension group) which slightly different with $4.33 \pm 1.11 \mathrm{~mm}$ (non-hypertension group). PGE2 level was higher in non-hypertension group 64.66 (20.79) pg/mL than in hypertension group $47.35(17.94) \mathrm{pg} / \mathrm{mL}$

The comparative test (*Mann-Whitney U-test) in Table 2 showed that there were significant differences in the subject of hypertension and non-hypertension on statistical levels of PGE2 $p=0.002(p<0.005)$.

Table 1: Clinical characteristic of the periodontal parameter in subject with hypertension and non-hypertension

\begin{tabular}{lllll}
\hline & Hypertension & & Non-hypertension & p value \\
& Mean (SD) & & Mean (SD) & \\
\hline $\begin{array}{l}\text { Sociodemography } \\
\begin{array}{c}\text { Age (years) } \\
\text { Clinical parameter }\end{array}\end{array}$ & $70.15(8.41)$ & $45.72(12.62)$ & 0.053 \\
$\quad \begin{array}{llll}\text { Plaque index } \\
\text { Calculus index }\end{array}$ & $1.72(0.82)$ & $1.02(0.44)$ & 0.163 \\
Debris index & $1.65(0.92)$ & $1.27(0.72)$ & 0.181 \\
Oral hygiene index & $2.97(1.90)$ & $0.86(0.45)$ & 0.073 \\
Pocket depth (mm) & $5.47(1.13)$ & $4.86(0.86)$ & 0.002 \\
Recession (mm) & $5.57(2.9)$ & $1.78(1.55)$ & 0.001 \\
Clinical attachment & $10.93(3.69)$ & $6.06(2.46)$ & 0.001 \\
loss (mm) & & & 0.001 \\
$\quad$ Bleeding on probing & $1.54(1.01)$ & $1.26(0.90)$ & 0.200 \\
$\quad$ PGE2 (pg/mL) & $47.35(17.94)$ & $64.66(20.79)$ & 0.013 \\
\hline Distribution data test; significant p>0.05 & &
\end{tabular}


Comparative analysis of the clinical periodontal parameter in Table 3 showed that there was a significant difference in index plaque, recession, $\mathrm{PD}$, and CAL $\mathrm{p}=0.01(\mathrm{p}<0.05)$, but there were no significant differences in other clinical periodontal parameters between subjects with hypertension and non-hypertension ( $p>0.05)$.

Inflammatory mediators in GCF have been considered as biomarkers of the progression and severity of periodontitis, as well as indicators of response to treatment. In this study, the mean concentration of PGE2 in the GCF was lower in the hypertension group than in non-hypertension group, Table 1 . The previous study population subjects age between 18 and 77 years old mentioned that PGE2 production seems to be modified by age and as the immune response ages, the immune system ages may decline as well [16].

The previous studies have evaluated the association between periodontal disease and hypertension. So far, little are known about the phenomena of this association, Table 3 shows that there was a significant difference in clinical periodontal parameter between hypertension and non-hypertension group. These results reveal with scientific evidence a possible connection between periodontal disease and systemic inflammation which in turn is associated with an increased risk of hypertension [5]. Contradictory, analysis of the Third National Health and Nutrition Examination Survey data result did not show any association between the severity of periodontal disease and blood pressure measurement [8].

The present study population is older compared to previous publications which suggest that local and perhaps consequent systemic inflammation might play a greater role in blood pressure control among the elderly. The relationship between periodontitis and hypertension is pivotal to the progression of cardiovascular disease because it is affected by the degree of blood pressure by people with hypertension. Existing studies report a variety of measurements of periodontal disease and use different definitions of hypertension outcomes [17].

Production of prostaglandin depends on the synthases activity of cyclooxygenase (COX), bifunctional enzymes that contain both COX and peroxidase [18]. The type of prostanoid production is determined by the differential expression of these enzymes within cells present at sites of inflammation. During the inflammatory response, inflammatory mediators activate the transcription of target genes, such as COX-2 and mPGES-1, and regulate PGE2 synthesis by activating the NF- $\kappa B$ pathway [19]. In chronic inflammation, PGE2 levels in GCF (Table 3)

Table 2: Comparative analysis level of PGE2 in hypertension and non-hypertension periodontitis subjects

\begin{tabular}{lllll}
\hline $\begin{array}{l}\text { Periodontitis } \\
\text { subject }\end{array}$ & $\mathbf{n}$ & \multicolumn{2}{l}{ PGE2 $(\mathbf{p g} / \mathbf{m L})$} & \multirow{2}{*}{ p value } \\
\cline { 2 - 4 } & & Median & Min-Max & \\
\hline Hypertension & 44 & 51.08 & $10.16-80.26$ & 0.002 \\
Non-hypertension & 18 & 68.57 & $9.75-94.79$ & \\
\hline
\end{tabular}

Mann-Whitney U-test; significant $\mathrm{p}<0.05$ showed significant differences with clinical parameters of BOP. PGE2, a blood pressure regulator, is a mediator for the inflammatory response also involved in gastrointestinal integrity, and it plays a role in fertility. However, the involvement of PGE2 in the resolution of inflammation has also been suggested [20].

PGE2 is a major mediator in the inflammatory response, blood pressure regulator, gastrointestinal integrity, and fertility. During the inflammatory response, the inflammatory mediators activate the transcription of target genes such as COX-2 and mPGES-1 and regulate PGE2 synthesis by activating the NF- $\kappa B$ pathway [21]. However, it has also been suggested that PGE2 could be involved in the resolution of inflammation [22]. Prostaglandins (PGs) are formed by a sequential series of three enzymatic reactions: Release of AA from AA derived from phospholipid membranes in phospholipases, conversion of AA to an unstable endoperoxide intermediate $\mathrm{PGH}_{2}$ by $\mathrm{COX}$, and isomerization prostaglandin $\mathrm{H}_{2}$ becomes bioactive prostanoid such as PGE2, prostacyclin, prostaglandin $\mathrm{F}_{2}$, prostaglandin $\mathrm{D}_{2}$, and thromboxane $A_{2}$ by distinct terminal synthases [22]. These findings were in line with Table 3 that showed at PD which has significant difference statistically.

A previous study by Andrew et al. found that the mean plaque and gingivitis scores were higher in patients with gingival overgrowth secondary to anti-hypertension agents (than those without gingival overgrowth), but there was also no significant difference of mean plaque and gingivitis scores between the two groups [23]. This was in line with comparative analysis (Table 3 ) that showed a significant difference in PD, recession, and CAL $(\mathrm{p}<0.05)$ with Gaetti-Jardim et al. study that reported patients with underlying cardiovascular disease and chronic periodontitis showed higher mean plaque score, probing $\mathrm{PD}$, and CAL compared to periodontally healthy subjects [24].

This study has several limitations. Arterial pressure directly corresponds to cardiac output, arterial elasticity, and peripheral vascular resistance [25]. Blood pressure is remarkably easy to alter and can be affected by many activities. In as much as the blood pressure measurements were taken on only one occasion, dayto-day variations in blood pressure may have resulted in random misclassification of our outcome measure of high blood pressure. In this study, high blood pressure in the patients can be produced by PGE2 receptors 1 and 3 [22].

The renin-angiotensin-aldosterone system relies on several hormones that act to increase blood volume and peripheral resistance. It begins with the production and release of renin from juxtaglomerular cells of the kidney. In our study, the functional condition of the kidney was not addressed because the evidence that referred to the relationship of periodontal disease with the kidney did not show significant results [26]. Furthermore, due to a relatively small sample size, there was not enough statistical power for some of the subgroup analysis. Given the limitations of this study, further studies are needed to confirm this association in other populations.

Table 3: Comparative analysis between clinical periodontal parameter in hypertension and non-hypertension

\begin{tabular}{|c|c|c|c|c|c|}
\hline \multirow[t]{2}{*}{ Clinical periodontal parameter } & \multicolumn{2}{|c|}{ Hypertension $(n=44)$} & \multicolumn{2}{|c|}{ Non-hypertension $(n=18)$} & \multirow[t]{2}{*}{ p value } \\
\hline & Median & Min-Max & Median & Min-Max & \\
\hline Plaque index & 1.65 & $0.08-3$ & 0.98 & $0.50-1.70$ & 0.001 \\
\hline Calculus index & 1.46 & $0.11-4.5$ & 1.07 & $0.38-2.75$ & 0.072 \\
\hline Debris index & 1.13 & $0.00-3$ & 0.65 & $0.26-2.1$ & 0.138 \\
\hline Oral hygiene index & 2.94 & $0.08-6$ & 1.41 & $1.01-3.8$ & 0.009 \\
\hline Pocket depth (mm) & 5 & $3-8$ & 4 & $3-7$ & 0.001 \\
\hline Recession $(\mathrm{mm})$ & 5 & $0-12$ & 1 & $0-7$ & 0.001 \\
\hline Clinical attachment loss (mm) & 10 & $4-20$ & 6 & $2-14$ & 0.001 \\
\hline Bleeding on probing & 1.38 & $0.00-4$ & 0.96 & $0-2.86$ & 0.153 \\
\hline
\end{tabular}

Mann-Whitney U-test; significant $\mathrm{p}<0.05$ 


\section{CONCLUSION}

PGE2 level in GCFin periodontitis patient with hypertension may indicate the risk of severe periodontal disease compares to non-hypertension patients. Resolution PGE2 in inflammation such periodontitis may increase alveolar bone resorption. Higher blood pressure may have a potential risk of periodontal disease. Expression of EP has to further investigation of the role in hypertension and periodontal disease. PGE2 can be one of the markers in seeing periodontal destruction. Further studies are needed to confirm the result of this study.

\section{ACKNOWLEDGMENT}

This project was supported by PITTA Grant Scheme 2019, Universitas Indonesia.

\section{AUTHORS' CONTRIBUTIONS}

All the authors have contributed equally.

\section{CONFLICTS OF INTEREST}

Declared none.

\section{REFERENCES}

1. Buford TW. Hypertension and aging. Ageing Res Rev 2016;26:96-111.

2. Nayor M, Stevenson MD, Musani SK, Xanthakis V, LaVealley MP, Larson MG, et al. Incidence of cardiovascular disease in individuals affected by recent changes to U.S. blood pressure treatment guidelines. J Hypertension 2018:36:436-43.

3. Pikir BS, Andrianto, Aritonang FAE. The difference of blood pressure and arterial stiffness after intake of arabica and robusta coffee in controlled hypertension. Folia Med Indones 2017;53:209-16.

4. Preshaw MP. Periodontal disease pathogenesis. In: Carranza's Clinical Periodontology. $13^{\text {th }}$ ed. Philadelphia, PA: Elsevier, Inc.; 2018. p. 4512,466-7.

5. Rivas-Tumanyan S, Campos M, Zevallos JC, Joshipura KJ. Periodontal disease, hypertension, and blood pressure among older adults in Puerto Rico. J Periodontol 2013;84:203-11.

6. Holmlund A, Holm G, Lind L. Severity of periodontal disease and number of remaining teeth are related the prevalence of myocardial infarction and hypertension in a study based on 4.254 subjects. J Periodontol 2006;77:1173-8.

7. Rivas-Tumanyan S, Spiegelman D, Curhan GC, Forman JP, Joshipura KJ. Periodontal disease and incidence of hypertension in the health professionals follow-up study. Am J Hypertension 2012;25:770-6

8. Aiuto FD, Sabbah W, Netuveli G, Donos N, Hingorani AD, Deanfield J, et al. Association of the metabolic syndrome with severe periodontitis in a large U.S. population-based survey. J Clin Endocrin Metabol 2008;93:3989-94.

9. Swan CE, Breyer RM. Prostaglandin $E_{2}$ modulation of blood pressure homestasis: Studies in rodent model. J Prostaglandins Other Lipid Mediat 2011;96:10-3.

10. Belibasakis GN, Guggenheim B. Induction of prostaglandin E2 and interleukin-6 in gingival fibroblast by oral biofilm. FEMS Immunol Med Microbiol 2011;63:381-6.

11. Camargo GACG, Santos MP, Silva NLC, Miranda ALP, Tributino JLM. Levels of prostaglandin $\mathrm{E}_{2}$ (PGE2) in gingival crevicular fluid from smokers and non-smokers with gingivitis and chronic periodontal disease. J Dent Oral Hyg 2015;7:54-9.

12. Subrahmanyam MV, Sangeetha M. Gingival crevicular fluid a marker of the periodontal disease activity. Indian J Clin Biochem 2003;18:5-7.

13. Papapanou PN, Sanz M, Buduneli N, Dietrich T, Feres M, Fine DH, et al. Periodontitis: Consensus report of workgroup 2 of the 2017 world workshop on the classification of periodontal and peri-Implant diseases and conditions. J Periodontol 2018;89:173-82.

14. Mishra B, Sinha ND, Gidwani H, Shukla SK, Kawatra A, Mehta SC. Equipment errors: A prevalent cause for fallacy in blood pressure recording a point prevalence estimate from an Indian health university. Indian J Commun Med 2013;38:15-21.

15. Beevers G, Lip GYH, O’Brien E. ABC of hypertension. Blood pressure measurement. Part I-sphygmomanometry: Factors common to all techniques. BMJ Clin Res 2001;322:981-5.

16. Nonnenmacher C, Helms K, Bacher M, Nüsing RM, Susin C, Mutters R, et al. Effect of age on gingival crevicular fluid concentrations of MIF and PGE2. J Dent Res 2009;88:639-43.

17. Aguilera EM, Suvan J, Buti J, Czesnikiewics-Guzik M, Ribeiro AB, Orlandi M, et al. Periodontitis is associated with hypertension: A systematic review and meta-analysis. Cardiovasc Res 2019;116:28-39.

18. Ricciotti E, FitzGerald GA. Prostaglandins and inflammation. J Am Heart Associat 2011;31:986-1000.

19. Gomez I, Foudi N, Longrois D, Norel X. The role of prostaglandin $E_{2}$ in human vascular inflammation. Prostaglandins Leukot Essent Fatty Acids 2013;89:55-63.

20. Rajakariar R, Hilliard M, Lawrence T, Trivedi S, Colville-Nash P, Bellingan G, et al. Hematopoietic prostaglandin D2 synthase controls the onset and resolution of acute inflammation through PGD2 and 15-deoxy Delta12 14 PGJ2. Proc Natl Acad Sci USA 2007;104:20979-84.

21. Lisowska B, Kosson D, Domaracka K. Lights and shadows of NSAIDs in bone healing: The role of prostaglandins in bone metabolism. Drug Des Devel Ther 2018;12:1753-8.

22. Yang T, Du Y. Distinct roles of central and peripheral prostaglandin E2 and EP subtypes in blood pressure regulation. Am J Hypertens 2012;25:1042-9.

23. Andrew W, Evelyn W, Francis M, Mark J, Mark C. Pattern of gingival overgrowth among patients on antihypertensive pharmacotherapy at a Nairobi Hospital in Kenya. Open J Stomatol 2014;4:169-73.

24. Gaetti-Jardim EJ, Marcelino SL, Feitosa ACR, Romito GA, Avila-Campos MJ. Quantitative detection of periodontopathic bacteria in atherosclerotic plaques from coronary arteries. J Med Microbiol 2009;58:1568-75.

25. Lionakis N, Mendrinos D, Sanidas E, Favatas G, Georgopoulou M. Hypertension in the elderly. World J Cardiol 2012;4:135-47.

26. Wahid A, Chaudhry S, Ehsan A, Butt S, Khan AA. Bidirectional relationship between chronic kidney disease and periodontal disease. Pak J Med Sci 2013;29:211-5. 